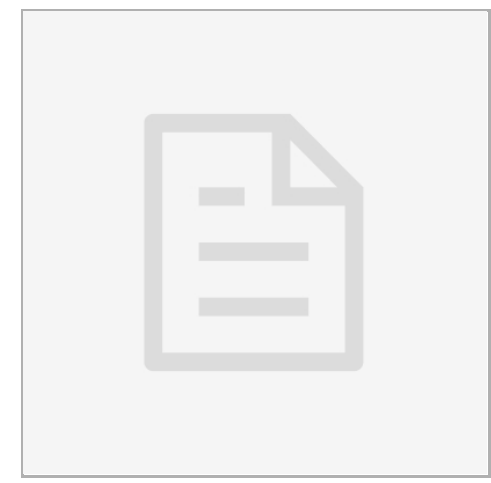

APR 27, 2021

\section{open ठaccess}

\section{DOI:}

dx.doi.org/10.17504/protocol s.io.baamiac6

\section{Protocol Citation: Clara} Huesing, Heike Muenzberg, Rui Zhang, Nathan Lee, Emily Qualls-Creekmore, Marie Francois 2021. Pseudorabies virus (PRV) injection into inguinal white adipose tissue. protocols.io

https://dx.doi.org/10.17504/p rotocols.io.baamiac6

License: This is an open access protocol distributed under the terms of the Creative Commons Attribution License, which permits unrestricted use, distribution, and reproduction in any medium, provided the original author and source are credited

Protocol status: Working We use this protocol and it's working

Created: Dec 09, 2019

Last Modified: Apr 27, 2021

PROTOCOL integer ID: 30765

\title{
(3) Pseudorabies virus (PRV) injection into inguinal white adipose tissue
}

Clara

Huesing $^{1}$,

Emily Qualls-

Creekmore $^{1}$,

1Pennington Biomedical Research Center

\section{SPARC \\ Tech. support email: info@neuinfo.org}

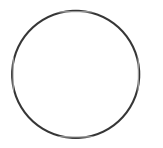

Clara Huesing

Pennington Biomedical Research Center

\section{ABSTRACT}

We utilize pesudorabies virus (PRV) retrograde tracing in combination with reporter mice, iDISCO, and confocal/light sheet microscopy to identify the location of preand post-ganglionic neurons as well as nerves that selectively innervate the iWAT in the mouse.

\section{GUIDELINES}

Virus stock needs to be placed on ice during surgeries. 


\section{MATERIALS}

- BSL2 surgery room and animal housing

- Container filled with ice to transport and store virus during surgery, outside clearly marked as biohazard

- Surgery cards and surgery record

- Personal protective equipment (PPE): hair bonnet, gloves, face mask, eye protection

- Ophthalmic lubricant

- Timer

- Biohazard stickers

- Bupivacaine/lidocaine

- $500 \mathrm{nl}$ blunt syringe with pulled glass pipette (Alternative is $1 \mathrm{~nL}$ beveled Hamilton syringe)

- Aluminum foil (for easy cleanup of the virus work area)

- Kimtech paper

- Biohazard waste container for virus waste

- Sterile towels

- Sterile surgical tools (scissors, hemostats, tissue forceps, teethed forceps)

- Sterile wound clip remover

- Sterile wound clips ( $7 \mathrm{~mm})$

- Sterile cotton swabs and gauze

- Isoflurane vaporizer, oxygen tanks, and anesthesia induction chamber

- Glass bead sterilizer

- Heating pads for surgery and recovery

- Pseudorabies virus stock (PRV-152) http://www.cnnv.pitt.edu/PRVtable.pdf

- Bupivacaine/lidocaine

- Carprofen

- Sterile saline

- Novalsan

- $70 \%$ isopropyl rubbing alcohol

- $70 \%$ Ethanol

- Distilled H2O

- $0.5 \mathrm{~mL}$ syringes (bupivacaine/lidocaine and carprofen injections)

- $3 \mathrm{~mL}$ syringes (saline injection)

- $70 \%$ ethanol spray bottle

- Mini centrifuge for spinning down virus 
(1) For virus transport one must adhere to IBC safety rules, doublecontainers are required for safe transport of biohazards (e.g. Eppendorf tube placed into $50 \mathrm{~mL}$ Falcon tube).

- All containers that are in contact with virus waste need to be properly labeled as biohazard waste.

- Surgery must be conducted in a BSL2-designated area

\section{BEFORE START INSTRUCTIONS}

- Approval of Institutional Biosafety Committee (IBC) to work with PRV

- Approval of Institutional Animal Care and Use Committee (IACUC) to perform PRV injections in animals

\section{Room preparation}

1 Turn on the glass bead sterilizer

2 Turn on the two heating pads (stereotaxic platform and designated area for recovery)

3 Place a non-sterile towel on your recovery heating pad and a sterile towel on the stereotaxic platform heating pad

4 Place a sterile towel to the right of the stereotaxic platform along with your rack with the three tubes filled with 'Novalsan', '70\% Isopropanol' and 'Empty'

$5 \quad$ Place multiple sterile cotton swabs into each $50 \mathrm{~mL}$ tube 
6 Put an empty cage half way on the recovery heating pad

$7 \quad$ Fill one $3 \mathrm{~mL}$ syringe completely with sterile saline, place underneath your stereotaxic heating pad to warm fluid

$8 \quad$ Fill your $3 \mathrm{~mL}$ syringes with sterile saline $(\sim 1.5 \mathrm{ml}$ for $25 \mathrm{~g}$ mouse), place underneath your recovery heating pad to warm fluid

$9 \quad$ Fill your $0.5 \mathrm{ml}$ syringes with Bupivacaine/lidocaine $(0.1 \mathrm{ml})$

10 Open the 02 tank valve, set the 02 level to $1 \%$ on the anesthesia machine

11 Check your isoflurane level on your anesthesia machine, set to $5 \%$ for the induction box

12 Place all of your surgical tools along with your eye lubricant, wound clip applicators, spare wound clips, sterile gauze and timer on your sterile towel to the right of your stereotaxic platform

\section{Virus preparation}

13 Place aluminum foil on clean surface, this will be the designated area to test and fill syringe with PRV 
14 Place rack with three tubes filled with '70\% Ethanol', 'dH2O', Waste

15 Test flow of syringe by filling with $\mathrm{dH} 2 \mathrm{O}$ and flushing several times. If you do not observe a steady flow of water out of the syringe, one must replace the syringe as this indicates the virus will not be properly administered.

\section{Pre-incision}

16 Record the mouse's body weight and (if applicable) ear tag number.

17 Place mouse into induction chamber with isoflurane set to $5 \%$.

18 Once the mouse is unconscious, turn your isoflurane to $1.8 \%$ (adjust this number according to the mouse's breathing), open your stereotaxic valve, close your induction box valve and place into the stereotaxic nose cone, using a cotton swab to align its incisors into the hole.

19 Secure your nose cone by tightening the top screw, gently tug on the base of the mouse's tail to check if its incisors are inside the hole and the mouse is secured in the cone.

20 Gently pull one of the mouse's hind limbs to check its withdrawal reflex for anesthetic depth.

$21 \quad$ Lubricate the mouse's eyes 
22 Spray interscapular region with a small amount (enough to cover carprofen injection spot) $70 \%$ ethanol and inject carprofen (10ul-20ul/gram body weight) subcutaneously.

23 Place a kimwipe underneath the mouse and shave the right dorsolumbar region of the mouse and remove all hair

24 Wipe loose fur off mouse using kimwipe placed underneath mouse

25 Disinfect freshly shaved area by lightly scrubbing skin with cotton swabs soaked in isopropanol and Novalsan. Perform three alternating scrubs of isopropanol then Novalsan.

\section{Incision}

26 Start your incision by pulling straight up on the skin at the midline of the back, parallel to the hip with forceps and make a transverse cut that extends the length of the dorsolumbar portion of the iWAT fat pad.

27 Using a sterile cotton swab, remove any connective tissue underneath your incision to spread incision apart.

28 Remove connective tissue underneath the skin incision using a sterile cotton swab until the iWAT depot is fully accessible.

29 Opt;font-family:"Times New Roman",serif'>Apply sterile saline to sterile gauze and place it over the iWAT to keep the tissue moist, then prepare the Hamilton syringe for injection. 
30 Fill syringe with PRV-152 virus, return to the surgery platform with syringe to begin injections.

31 Remove the saline-soaked gauze from the iWAT

32 Administer injections (10x200nl) into the right iWAT pad and hold the syringe in place for $~ 30$ seconds after each injection to minimalize backflow, slowly pull the syringe out of the iWAT while holding a sterile cotton swab on the site of injection to dry of any possible virus leakage.

32.1 Note: Syringe should be held parallel, not perpendicular, to the fat pad while injecting. This will help prevent piercing into the peritoneal wall, causing off-target labeling

33 Place a fresh, saline-soaked gauze on top of the iWAT and clean the syringe with 4-5 alternating flushes of $70 \%$ ethanol and $\mathrm{dH} 2 \mathrm{O}$. Collect flushed liquid and dispose as biohazard waste

\section{Closing incision}

34 Remove the saline-soaked gauze from the iWAT and with a sterile cotton swab and teethed forceps, reposition the overlaying skin back to its original location prior to incision.

35 With teethed and tissue forceps, pull up on the skin surrounding the incision in order to align both sides of incision properly, and with tissue forceps, begin going along the incision ensuring that the subcutaneous layer of skin is not sticking out past the external layer of the skin to ensure proper healing of incision.

36 Using teethed forceps and wound clip applicators, start at the side of the incision closest to the midline, and administer wound clips $\sim 25 \mathrm{~mm}$ apart from one another to allow for proper blood 
circulation for healing of the incision.

37 Once you have applied a sufficient amount of wound clips (usually 4-5), use your hemostats to tighten each of the wound clips to avoid the mouse scratching them off. Make sure not to tighten them too much or they will cause irritation and poor circulation around the wound.

38 Using teethed forceps, gently lift up skin at one end of incision and inject $0.05 \mathrm{~mL}$ of bupivacaine/lidocaine subcutaneously. Repeat at other end of incision.

39 Turn isoflurane off, loosen up the nose cone and remove the mouse's incisors with the wooden end of a cotton swab from the hole on the mount.

40 Scruff the mouse and turn it over to inject $\sim 1.5 \mathrm{~mL}$ (for a $25 \mathrm{~g}$ mouse) of warm saline intraperitoneally

$41 \quad$ Place the unconscious mouse on the warm side of the cage that is half way on the recovery heating mat. Place mouse on its side.

42 Using water from animal's cage, wet a chow pellet and place on floor of cage so mouse can easily access food.

43 Place any tools used during surgery in the glass bead sterilizer for 15-20 seconds and change gloves.

\section{Post-operative Care}

441 day post-op: Administer carprofen subcutaneously (approx. 10ul/g bw), record weight of mouse, health check 
452 days post-op: Administer carprofen subcutaneously (approx. 10ul/g bw), record weight of mouse, health check

$463-7$ days post-op: record weight of mouse, health check

4710 days post-op: remove wound clips, replace PVC pipe in cage 